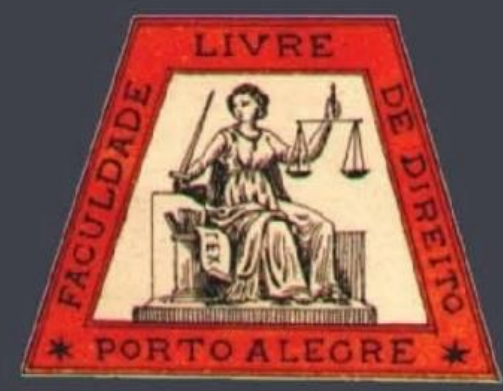

\title{
Violação de direitos humanos por agentes da polícia no ato da investigação
}

\begin{abstract}
Human rights violation by police officers in the act of crime investigation
\end{abstract}

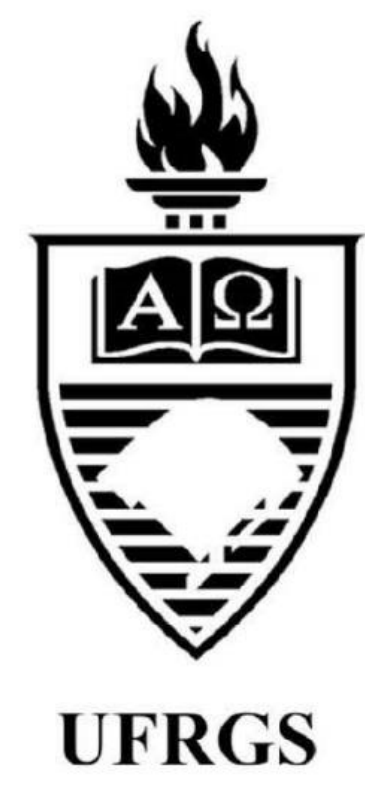

\author{
David Adriano Nota \\ Universidade Federal do Rio Grande do Sul \\ Tupinambá Pinto de Azevedo \\ Universidade Federal do Rio Grande do Sul
}




\title{
Violação de direitos humanos por agentes da polícia no ato da investigação criminal
}

\author{
Human rights violation by police officers in the act of crime investigation
}

David Adriano Nota*

Tupinambá Pinto de Azevedo**

\section{REFERÊNCIA}

NOTA, David Adriano; AZEVEDO, Tupinambá Pinto de. Violação de direitos humanos por agentes da polícia no ato da investigação criminal. Revista da Faculdade de Direito da UFRGS, Porto Alegre, n. 36, p. 55-72, ago. 2017.

\begin{abstract}
RESUMO
Este artigo buscou identificar ações concretas que possam ser desenvolvidas para evitar torturas perpetradas por agentes da polícia no ato da investigação criminal em Moçambique. Entrevistas e questionários dirigidos aos agentes que compõem o sistema de administração da justiça possibilitaram perceber as causas que levam os policias a pautar pela tortura no ato da investigação criminal e identificar ações para evitá-la. A pesquisa mostrou que para evitar torturas no ato da investigação criminal, em Moçambique, é necessário criar uma lei própria e exclusiva que defina, incrimine e traga uma moldura penal abstrata do crime de tortura, e que o Estado mantenha a revisão e a formação sistemática de regras de interrogatórios e métodos de investigação aos agentes aplicadores das leis, e não só, o Estado deve criar condições para que o advogado do suspeito se faça presente no primeiro interrogatório policial.
\end{abstract}

\section{PALAVRAS-CHAVE}

Tortura. Polícia. Direitos Humanos. Investigação criminal.

\section{ABSTRACT}

This paper aims to identify concrete actions that can be developed to prevent police officers from torture suspects during the crime investigation act in Mozambique. Through interviews and questionnaires with the agents that forms the justice administration system, it was possible to understand what causes the police have to torture suspects in the crime investigation act and to identify actions to prevent it. Research has shown that to prevent torture in the crime investigation act it is necessary to create a separate and exclusive law in order to define, incriminate and bring a criminal abstract frame of the crime of torture; the state must hold a review and make a systematic formation with training rules for interrogation and investigation methods to all law enforcers agents so as to create conditions for the suspect's lawyer to be present in the first police inquiry.

\section{KEYWORDS}

Torture. Police. Human rights. Crime investigation.

\section{SUMÁRIO}

Introdução. 1. A tortura como prática ilegal e desumana para a obtenção de provas na investigação criminal. 1.1. Aspectos conceituais da tortura. 1.2. Características do crime de tortura. 1.3. A tortura e a sua influência negativa na investigação criminal. 2. Discussão e análise dos resultados. 2.1. Narrativas dos detidos/reclusos na penitenciaria provincial de Tete quanto à tortura praticada pela polícia durante a detenção e o interrogatório. 2.2. Causas que contribuem para que ocorra a tortura no ato de investigação do crime pela polícia moçambicana. 2.3. A inexistência de uma lei sobre a tortura em Moçambique e a sua implicação na responsabilização criminal de seus violadores. Conclusão. Referências.

\section{INTRODUÇÃO}

\footnotetext{
* Doutorando em Ciência Política (Universidade Federal do Rio Grande do Sul - UFRGS). Mestre em Direito (UFRGS, 2016). Licenciado em Ciências Policiais (Academia de Ciências Policiais - ACIPOL, Moçambique, 2010). Oficial da Polícia da República de Moçambique.

${ }^{* *}$ Foi professor da Faculdade de Direito da UFRGS em nível de graduação e de pós-graduação. Com ingresso em 1971, fez carreira no Ministério Público do Estado do Rio Grande do Sul. No ano de 1994, assumiu cargo de Desembargador do Tribunal de Justiça do Estado do Rio Grande do Sul. Doutor em Direito do Estado e Teoria do Direito (Universidade Federal do Rio Grande do Sul - UFRGS, 2005). Especialista em Direito Penal (Faculdade de Direito de Cruz Alta, 1978). Graduado em Ciências Jurídicas e Sociais (Pontifícia Universidade Católica do Rio Grande do Sul - PUCRS, 1967).
} 
Em um Estado de Direito, a atividade policial deve ser exercida observando os direitos fundamentais do homem; daí o imperativo de se evitar o uso da tortura e de tratamento desumano ou degradante como um de seus princípios norteadores, adotando, em vez disso, as formas de investigação criminal legalmente instituída para proteger os direitos humanos.

Assim sendo, em nenhum Estado que preze ser de direito, a violação dos direitos fundamentas do homem deve prevalecer. Isso quer dizer que, em qualquer Estado de Direito, o respeito e a proteção dos direitos fundamentais do homem deve predominar independentemente das razões e circunstâncias. Para isso, devem ser respeitadas as normas, os princípios constitucionais $\mathrm{e}$ as garantias dadas ao indivíduo, para que não haja abusos e nem violações aos seus direitos e a sua dignidade enquanto ser humano.

Nesse sentido, enfatiza-se o papel da Constituição da República, uma vez que nele estão definidos os limites e as regras para o exercício do poder estatal, onde estão descritos os Direitos e Garantias fundamentais dos cidadãos.

A República de Moçambique é um Estado democrático e de Direito, baseado no respeito e na garantia dos direitos e liberdades fundamentais do homem de modo que todo cidadão tem direito à vida e à integridade física e moral, não podendo estar sujeito à tortura ou tratamentos cruéis e desumanos, conforme o Artigo $3^{\circ}$, combinado com o número $1^{\circ}$ do artigo $40^{\circ}$, ambos presentes na CRM (Constituição da República de Moçambique).

Mesmo com a Constituição da República claramente proibindo a tortura, em Moçambique não existe uma lei que defina, tipifique e incrimine a tortura, o que faz da prevenção e do combate à tortura no país um fracasso. Segundo relatos da Amnistia internacional, bem com relatórios produzidos pela Liga dos Direitos Humanos de Moçambique, essa grave violação dos direitos humanos ainda ocorre em instituições de privação de liberdade, como, por exemplo, esquadras de polícia e penitenciárias.

De acordo com o Jornal Notícias (2013), a Liga dos Direitos Humanos (LDH) apresentou, em 09 de maio de 2013, na $1^{\text {a }}$ Conferência Nacional sobre o papel da Polícia em um Estado Democrático e de Direito, em Moçambique, dados indicando que, em 2012, foram reportados para a LDH um total de 161 casos de tortura, abuso e violação dos direitos humanos envolvendo agentes da Polícia da República de Moçambique (PRM) no exercício das suas funções, o que representa um aumento significativo em comparação ao ano de 2011, no qual foi tramitado um total de 91 casos.

Além dos dados apresentados acima, a Ordem dos Advogados de Moçambique (OAM), no discurso de abertura do ano judicial, em 02 de março de 2015, na Assembleia da República, reiterou que a PRM prende ou detém cidadãos sem qualquer tipo de prova, sendo que os detidos apresentam sinais claros de violência física, perpetrada pela polícia, cuja finalidade é obter informação ou confissão da vítima, ou seja, castigá-la para fins de procedimento jurídico destinado à produção de prova em juízo ou até fora dele. Salientou-se, ainda, que a polícia não pode e nem deve usar de meios ilegais para mostrar serviço, devendo usar exclusivamente de meios legalmente estatuídos para a obtenção de prova criminal (OAM, 2015).

Diante desse cenário, a presente pesquisa propõe-se a identificar o que faz com que os agentes da polícia de Moçambique optem pelo tratamento desumano (torturas) e quais ações concretas podem ser desenvolvidas para evitar a tortura por eles perpetrada. Assim sendo, para orientar a pesquisa, formulou-se a seguinte questão norteadora: quais ações devem ser desenvolvidas para evitar torturas e violações de direitos humanos cometidos por agentes da polícia no ato da investigação criminal? 
No tocante aos aspectos metodológicos, a pesquisa guiou-se pela abordagem qualitativa combinada com a abordagem quantitativa, conforme segue.

Para a escolha da população-alvo, foram identificados todos os intervenientes diretos na administração da justiça, bem como os cidadãos detidos na penitenciária provincial de Tete. Os intervenientes diretos na administração da justiça são os membros da PRM, as autoridades judiciais (procuradores e juízes), os membros da LDH (Liga dos Direitos Humanos) e os advogados do Instituto de Patrocínio e Assistência Jurídica de Moçambique (IPAJ). Quanto à amostra, optou-se pela amostragem intencional, sendo selecionados 163 indivíduos subdivididos nas seguintes categorias: 120 reclusos cumprindo pena na penitenciária provincial de Tete, 30 agentes da polícia, 03 procuradores, 03 juízes, 04 membros da LDH e 04 membros do Instituto de Patrocínio e Assistência Jurídica.

No que se refere aos instrumentos de recolha de dados, utilizou-se os métodos de pesquisa bibliográfica, pesquisa documental, questionário e entrevista.

A pesquisa bibliográfica consistiu no levantamento, na leitura, discussão e análise de diversas obras de caráter científico de diferentes autores que abordam o tema em estudo e de alguma literatura independente desde que fundamentasse o tema em questão.

A pesquisa documental traduziu-se pela consulta aos documentos e registros relacionados aos objetivos da pesquisa em estudo para fins de coleta de informações úteis para o entendimento e a análise do problema. Esse instrumento de recolhimento de dados fez parte do processo de conhecimento e identificação do problema, sem o qual as soluções obtidas não teriam fundamento científico (MICHAEL, 2005). Vale salientar que os documentos consultados foram: leis e convenções sobre os direitos humanos, relatórios das instituições de administração da justiça de
Moçambique sobre a atuação policial e sobre os direitos humanos, relatórios da Liga dos Direitos Humanos de Moçambique, relatórios da Amnistia Internacional, e outros documentos oficiais que versam sobre o tema em questão.

No que diz respeito ao questionário, a pesquisa se baseou no questionário misto, o qual inclui perguntas abertas e fechadas que visam explorar mais o conhecimento do informante. De acordo com Michael (2005), o questionário misto é constituído por uma série ordenada de perguntas que devem ser respondidas por escrito e sem a presença do pesquisador. Por esse motivo, devese atentar para o cuidado na elaboração das perguntas para que não haja dificuldades de percepção, dado que o pesquisador não está presente para esclarecimentos.

Esse instrumento de obtenção de dados foi dirigido aos reclusos encarcerados na Penitenciária Provincial da cidade de Tete e aos membros da Polícia da República de Moçambique afetos no Comando Provincial da PRM - Tete.

No tocante às entrevistas, recorreu-se à entrevista dirigida. Optou-se por essa forma de entrevista porque, no entender de Campenhou e Quivy, ela permite ao investigador dispor de uma série de perguntas - guias abertas, a propósito das quais é imperioso receber uma informação da parte do entrevistado (CAMPENHOU; QUIVY, 1998). Temos de salientar que as perguntas guias abertas - permitem ao entrevistado expor os seus conhecimentos sobre a matéria sem limitações.

As entrevistas acima referidas foram dirigidas aos Magistrados do Ministério Público da cidade de Tete, aos juízes da Cidade de Tete, aos membros da Liga dos Direitos Humanos da cidade de Tete e aos advogados do Instituto do Patrocínio e Assistência Jurídica da cidade de Tete.

No que tange a análise da informação recolhida através do questionário e entrevistas, foi 
utilizada a técnica de análise de discurso e análise de conteúdo respectivamente.

Não só, os dados recolhidos através do questionário foram analisados estatisticamente com o auxílio do programa informático "SPSS". 1

É importante referir que nem todos os dados recolhidos tornaram-se objeto de análise, sendo destacados aqueles que se relacionam com os objetos e as respectivas hipóteses.

Para a segurança dos entrevistados, optamos por ocultar suas identidades, usando apenas suas funções institucionais.

\section{A TORTURA COMO PRÁTICA ILEGAL E DESUMANA PARA A OBTENÇÃO DE PROVAS NA INVESTIGAÇÃO CRIMINAL}

\subsection{Aspectos conceituais da tortura}

Etimologicamente, o termo tortura provém do latim cruciatus, que significa "suplício", e cruciamentum, que quer dizer "tormenta" (Dicionário de português, 2000, p. 532). Para os romanos, a palavra "tortura" remete à quaestio per tormenta, quaestio tormentorum ou, ainda, tormenta ou cruciatus - os dois últimos costumavam referir aos verdadeiros e próprios meios de submissão corporal. Quaestio era o interrogatório judiciário e, tormentum, seu instrumento, ou seja, a tortura no seu sentido atual, buscar a "verdade" a todo o custo através de uma confissão adquirida por meio de práticas abusivas (DI BELLA, 2008, p. 54-55).

De acordo com Mattoso (1984, p. 29), a tortura pode ser entendida como "todo sofrimento a que uma pessoa é submetida por outra, desde que de propósito da segunda e contra a vontade da primeira". Plácido e Silva (1958, p. 167) definem a tortura de uma forma mais ampla: "um sofrimento ou a dor provocada por maus tratos

\footnotetext{
${ }^{1}$ SPSS - Statistic Base é um software de análise estatístico que fornece os principais recursos necessários para executar um processo de análise estatística do início ao fim. O
}

físicos ou morais". Já Hungria (1958, p. 167) traduz a ideia de que a tortura é um "meio supliciante, a inflição de tormentos, a judiaria, a exasperação do sofrimento da vítima por atos de inútil crueldade". Para Aníbal Bruno (1966, p. 81), a tortura consiste no "sofrimento desnecessário e atormentador, deliberadamente infligido à vítima". Noronha (1977, p. 23), por sua vez, conceitua o termo como o ato de "infligir-se um mal ou sofrimento desnecessário e fora do comum".

Contudo, para a LDH moçambicana (2004, p. 13), considera-se tortura a atuação de um agente da polícia que, no exercício de suas funções de manutenção da ordem e tranquilidade públicas, agride fisicamente ou ameaça de maneira violenta um suspeito no ato de sua captura, interrogando-o e demandando sua confissão. Ainda de acordo com a LDH, a tortura define-se pelo ato de um agente da Polícia de Investigação Criminal (PIC) maltratar suspeitos durante os interrogatórios com o intuito de obter provas criminais a serem levadas aos Tribunais, bem como pela forma de atuação dos Magistrados do Ministério Público ou Judicial ao proferir ameaças na obtenção de provas durante as sessões de julgamento ou instrução contraditória.

De acordo com o Artigo $1^{\circ}$ da Convenção das Nações Unidas contra a Tortura e Outros Tratamentos ou Penas Cruéis, Desumanos ou Degradantes, adotados e proclamados, em 10 de dezembro de 1984, pela Resolução número 39/46 da Assembleia Geral das Nações Unidas, considera-se tortura qualquer ato através do qual, dores ou sofrimentos agudos, físicos ou mentais, são infligidos intencionalmente a uma pessoa a fim de obter dela ou de terceira pessoa informações ou confissões; de castigá-la por ato cometido por ela ou terceira pessoa, isto é, ato do qual ela é suspeita de ter cometido; de intimidá-la

programa inclui uma ampla faixa de procedimentos e técnicas para ajudar a expandir e conduzir a pesquisa, além de tomar decisões mais adequadas. 
ou coagi-la ou intimidar e coagir uma terceira pessoa; ou, ainda, por qualquer outra razão com base em discriminação de qualquer natureza, quando, por exemplo, dores ou sofrimentos são infligidos por um funcionário público ou outra pessoa no exercício de funções públicas, seja por sua instigação, seja com o seu consentimento.

Nesse sentido, para a convenção acima referida, aquele capaz de cometer o crime de tortura é justamente o Estado, através de seus servidores, pois é o Estado que têm a missão de garantir o bem-estar e a proteção dos cidadãos. Um cidadão comum não pode ser acusado de ter cometido o crime de tortura, mas, sim, crimes comuns que se encontram tipificados no Código Penal e outras legislações complementares. Em outras palavras, isso configura o crime de tortura como crime próprio de ser cometido somente por um funcionário público. É o Estado, através dos agentes de Defesa e Segurança, que parece fazer uso da prática de tortura para diversos fins, tais como obtenção de confissão, vingança ou perseguição política.

Na mesma linha da noção de tortura adotada pela Assembleia Geral das Nações Unidas, a Convenção Interamericana para Prevenir e Punir a Tortura, de 1985, em seu Artigo $2^{\circ}$, define a tortura como:

Todo o ato pelo qual são infligidos intencionalmente a uma pessoa pena ou sofrimentos físicos ou mentais, com fins de investigação criminal, como meio de intimidação, como castigo pessoal, como medida preventiva, como pena ou como qualquer outro fim. Entender-se-á também como tortura a aplicação sobre uma pessoa, de métodos tendentes a anular a personalidade da vítima, ou a diminuir sua capacidade física ou mental, embora não cause dor física ou angustia psíquica.

Portanto, a Convenção também considera tortura somente atos cometidos por funcionários do Estado, ao referir que a tortura é qualquer ato pelo qual são infligidos intencionalmente a uma pessoa pena ou sofrimentos físicos ou mentais com fins de investigação criminal, uma vez que quem possui o ius imperi de investigar e esclarecer o crime é o Estado mediante a Polícia e o Ministério Público.

No Brasil, nos termos do Artigo $1^{\circ}$, I, da Lei 9455/97, considera-se tortura o emprego violento ou a grave ameaça praticados por agentes do Estado ou por pessoas a serviço do Estado, de modo a causar sofrimento físico ou mental, quando a violência ou ameaça são infringidas com o fim de obter informações ou condições das vítimas ou de terceira pessoa.

É importante destacar que nem toda forma de violência física ou pressão psicológica, assim como nem todo ato de crueldade, pode ser enquadrada como tortura simplesmente. Para que um ato seja considerado tortura, a vítima torturada deve encontrar-se em circunstâncias totalmente desfavorecidas, privada de suas liberdades, garantias e faculdades (físicas ou morais) de modo que o infrator tenha total domínio do torturado. Caso contrário, enquadra-se em um tipo legal de crime comum do Código Penal.

A partir das noções de tortura apontadas acima, é possível fazer 04 (quatro) observações: (i) para que um ato seja considerado tortura, deve haver violência física ou psicológica. O elemento físico é composto por castigos corporais que provocam dor aguda a fim de obter a confissão do suspeito. O elemento psicológico é composto por atos intimidatórios ou de coação que provocam sofrimento sem dor física, porém, psicológica, com o mesmo objetivo de obter uma confissão ou uma determinada informação; (ii) a pessoa torturada não se encontra em condições de reagir, ou seja, devem estar anuladas suas capacidades físicas e mentais; (iii) tal violência deve ser praticada por um funcionário público no exercício das suas funções; e (iv) a finalidade da violência deve ser a de obrigar uma pessoa a dar informação ou confissão de um determinado ato que se supõe que tenha sido cometido por ela ou por terceira pessoa. 
Dessa forma, podemos sintetizar a noção de tortura como uma violência física ou psicológica praticada por um funcionário público no exercício das suas funções a fim de obter, do torturado ou de terceira pessoa, uma informação ou acontecimento. Assim, o conceito de tortura se circunscreve, exclusivamente, a atos praticados por agentes do Estado ou por indivíduos em que, no momento da prática da tortura, representavam o Estado ou estavam a exercício dele.

\subsection{Características do crime de tortura}

A tortura possui características particulares que a distinguem de outros tipos legais de crime. Assim sendo, Gomes (2001, p. 14-32) traduz a ideia de que, para que ocorra crime de tortura, é necessário o constrangimento contra alguém submissão, sujeição, anulação da liberdade de vontade, etc. -, o qual pode ocorrer de duas maneiras: a) mediante violência (força física sobre o corpo: agressão que cause prejuízo físico ou que afete o corpo e a mente, ou, sofrimento mental, tal como uso de drogas, suplício de água, privação do sono, etc.); ou b) mediante grave ameaça (a intimidação ou anúncio de um mal futuro, seja à vítima, seja a alguém que lhe é próximo). A ameaça grave afeta o intelecto, ou seja, há sofrimento mental.

Gomes (2001, p. 15-32) salienta que para que se configure o crime de tortura exige-se a finalidade particular de obter informação, declaração ou confissão da vítima ou de terceira pessoa. Qualquer outro objetivo do agente, como, por exemplo, se movido por sadismo ou vingança, não pode ser considerado crime de tortura, mas, sim, crime comum ao Código Penal; o crime de tortura propriamente dito consuma-se com o sofrimento físico ou mental da vítima, decorrente do seu constrangimento, não sendo imprescindível que se alcance a informação, declaração ou confissão pretendida. Pouco importa a natureza dos fatos em torno dos quais gira a declaração, confissão ou informação que se pretende obter: fato penal, comercial, pessoal etc. Por esse motivo, qualquer pessoa pode ser um sujeito ativo: tanto o funcionário público quanto o particular que esteja representando o Estado no momento do cometimento do crime de tortura (GOMES, 2001, p. 15-32).

Apoiado no Direito Comparado, o Artigo $1^{\circ}$ da Lei brasileira 9455/97, a qual define a tortura enquanto crime, afirma que o crime de tortura pode ser considerado se ocorrerem um dos fatos a seguir:

I - Constranger alguém com emprego de violência ou grave ameaça, causando-lhe sofrimento físico ou mental:

a) com o fim de obter informação, declaração ou confissão da vítima ou de terceira pessoa;

b) para provocar ação ou omissão de natureza criminosa;

c) em razão de discriminação racial ou religiosa;

II - Submeter alguém, sob sua guarda, poder ou autoridade, com emprego de violência ou grave ameaça, a intenso sofrimento físico ou mental, como forma de aplicar castigo pessoal ou medida de caráter preventivo.

Pena - reclusão, de dois a oito anos.

$\S 1^{\circ} \mathrm{Na}$ mesma pena incorre quem submete pessoa presa ou sujeita a medida de segurança a sofrimento físico ou mental, por intermédio da prática de ato não previsto em lei ou não resultante de medida legal.

Seguindo essa mesma linha, a Convenção das Nações Unidas contra a Tortura e Outros Tratamentos ou Penas Cruéis, Desumanos ou Degradantes, adotados e proclamados pela Resolução número 39/46 da Assembleia Geral das Nações Unidas, em 10 de dezembro de 1984, e a Convenção Internacional para Prevenir e Punir a Tortura, de 1985, nos seus Artigos $1^{\circ}$ e $2^{\circ}$, respectivamente, defendem que para que seja considerado um ato de tortura devem haver os seguintes elementos constitutivos do crime:

\footnotetext{
$\checkmark$ Infligir dores, sofrimentos agudos, físicos ou mentais a alguém com intenção de tirar dela ou da terceira pessoa confissão ou uma informação; $\checkmark$ Castigar alguém por ato que ela ou terceira pessoa tenha cometido, ou seja, suspeita de ter cometido;
} 
$\checkmark$ Intimidar ou coagir alguém ou outras pessoas; ou por qualquer motivo baseado em discriminação de qualquer natureza;

$\checkmark$ Os tais atos devem ser cometidos por um funcionário público ou outra pessoa no exercício de funções públicas, ou por sua instigação, ou com o seu consentimento.

Na obra "Vigiar e Punir - Nascimento da prisão", Foucault (2014) caracteriza a tortura de forma clara e simples, especialmente como espécie de punição dirigida diretamente ao "corpo dos condenados" e distinguida pela "ostentação dos suplícios" como uma demonstração do poder soberano ilimitado ao governante sobre seus súditos.

Muitas vezes, excetuando os inimputáveis por razão de doenças mentais, o crime de tortura é praticado dolosamente. ${ }^{2} \mathrm{O}$ torturador está consciente da prática do ato ilícito e, mesmo sabendo que está cometendo um crime, consuma o ato para atingir o seu objetivo. Nesse sentido, Beccaria (2007, p. 38) traduz a ideia de que o desejo pela prática do crime e pelos resultados do ato praticado é o que faz da tortura um crime hediondo, "monstruoso e absurdo".

Outra característica da tortura diz respeito ao seu local de ocorrência. Muitos casos ocorrem em locais ermos, de pouca visibilidade, onde quase não há testemunhas e a vítima acaba ficando com medo de represálias e da repetição do ato consigo própria ou com seus familiares, uma vez que, não raro, os torturadores ameaçam torturar membros da família da vítima em caso de denúncia. A falta de testemunhas e de denúncia dificulta a identificação do autor do crime, prejudicando, dessa forma, o seu procedimento jurídico. Mesmo que a perícia produza provas técnicas, ainda há a necessidade de provar a autoria criminal, dado que as vítimas, como dito, muitas vezes, não denunciam os autores do crime e, além disso, as autoridades da polícia, mesmo tendo conhecimento do torturador, não o denunciam a fim de protegê-lo e salvaguardar a imagem da instituição.

\subsection{A tortura e a sua influência negativa na investigação criminal}

No plano normativo, o Artigo $1^{\circ}$ da Lei 49/2008, de 27 de agosto - Lei portuguesa de Organização da Investigação criminal - define a Investigação criminal da seguinte maneira:

\begin{abstract}
Conjunto de diligências que, nos termos da lei processual penal, se destinam a averiguar a existência de um crime, determinar os seus agentes e a sua responsabilidade, descobrir e recolher as provas, no âmbito do processo criminal.
\end{abstract}

Marques (1997) define a Investigação Criminal como uma atividade Estatal de persecução criminal destinada a preparar a ação penal, a qual apresenta caráter preparatório e informativo, uma vez que seu objetivo é levar ao órgão encarregado da ação penal os elementos necessários para a dedução da pretensão punitiva em juízo.

O projeto sobre a proibição da captura e detenção arbitrárias, preparado a pedido da Comissão dos Direitos do Homem das Nações Unidas, através do Artigo 24 da resolução 27 (XVII), de 14 de março de 1961, estabelecia o seguinte:

Nenhuma pessoa capturada ou detida será sujeita a
coação física ou mental, tortura, violência, ameaças
ou qualquer forma de pressão, enganos, manobras
insidiosas, sugestões falaciosas, interrogatórios
prolongados, hipnose, administração de drogas ou
quaisquer outros meios tendentes a comprometer ou
a enfraquecer a sua liberdade de ação ou de decisão,
a sua memória ou o seu discernimento. Qualquer
declaração que a pessoa possa ser levada a proferir
através dos métodos acima proibidos, bem como
qualquer prova obtida em resultado dos mesmos, não elementos objetivos desse tipo e na vontade de praticá-los: a pessoa atua dolosamente quando conhece e quer os elementos objetivos de um tipo legal. 
será admitida como elementos de prova contra a pessoa em causa em qualquer processo [...].

Beccaria (2007, p. 38), na obra "Dos delitos e das penas", enfatiza que "é monstruoso e absurdo exigir que um homem se acuse a si mesmo e procurar fazer nascer à verdade por meio dos tormentos, como se essa verdade estivesse nos músculos e nas fibras do infeliz".

No entender de Verri (2000, p. 89), a tortura, em vez de ser um meio para descobrir a verdade, acaba por dificultar a descoberta da verdade criminal, visto que ela pode levar à confissão de inocentes e à resistência de culpados, dessa forma, condenando inocentes e absorvendo culpados. Assim sendo, Verri (2000, p. 89) afirma que "a tortura não constitui um meio para descobrir a verdade", mas, sim, "um convite para que tanto o culpado quanto o inocente se declarem culpados, o que constitui um meio para confundir a verdade, jamais para descobri-la".

A partir de Verri, cremos que a tortura cuja finalidade é obter provas na investigação criminal acaba por destorcer a verdade sobre os fatos, pois, a pessoa torturada, sendo ou não culpada, é levada a confessar o crime devido às intensas dores sofridas.

\section{DISCUSSÃO E ANÁLISE DOS RESULTADOS}

\subsection{Narrativas dos detidos/reclusos na penitenciaria provincial de Tete quanto à tortura praticada pela polícia durante a detenção e o interrogatório}

No total, 30 dos 90 reclusos $(33,4 \%)$ que responderam ao questionário na Penitenciária da Província de Tete afirmaram não terem sido submetidos a nenhuma coação física ou psicológica a fim de confessarem o seu envolvimento no crime do qual foram acusados; já os demais 60 reclusos $(66,6 \%)$ revelaram que foram submetidos à coação física ou psicológica durante o interrogatório na Esquadra da Polícia. Questionados sobre os instrumentos utilizados para obrigá-los a confessarem o crime de que eram suspeitos, 50 dos 60 reclusos $(83,3 \%)$ que relataram terem sido submetidos à tortura durante sua detenção disseram terem sido chicoteados com cassetete e sofrido agressão física à mão; os 10 restantes $(16,4 \%)$ afirmaram que tiveram os dedos apertados com alicate. Constatou-se que os 60 reclusos que foram submetidos à tortura durante o interrogatório policial no momento de sua detenção ou no interrogatório inicial não se fizeram presente com um advogado ou defensor oficioso, além disso, nenhuma das vítimas torturadas denunciou o crime ou registrou queixa por medo de represálias devido às ameaças de perseguição a seus membros familiares.

Esses resultados refletem o quanto a tortura é uma realidade durante o interrogatório policial, principalmente no que tange à investigação criminal com o intuito de se apurar a verdade sobre os fatos e indiciar os suspeitos de terem cometido o crime.

Diante dessa realidade, a Comissão Interamericana de Direitos Humanos defende que para garantir os direitos humanos e evitar que a tortura seja praticada no ato da investigação criminal e do interrogatório policial, o suspeito deve ser interrogado somente na presença de um advogado e de um juiz, e esse direito deve ser garantido desde o primeiro interrogatório policial, caso contrário, as provas obtidas não têm valor probatório em juízo (OEA, 1983, p. 100) - o que não aconteceu nos casos em apreço.

Curiosamente, os 30 reclusos que afirmaram não terem sido forçados a confessar o crime e nem submetidos à tortura ou tratamento degradante se fizeram presente com um advogado ou defensor oficioso durante o primeiro interrogatório policial. Isso corrobora com a ideia sustentada pela Comissão Interamericana de Direitos Humanos de que para se evitar a tortura dos suspeitos de ter praticado o crime durante o 
interrogatório policial, o acusado deve estar, sim, na presença de um advogado ou de um defensor oficioso atribuído pelo Estado, caso não tenha condições de contratar um advogado particular.

\subsection{Causas que contribuem para que ocorra a tortura no ato de investigação do crime pela polícia moçambicana}

Os entrevistados foram unânimes ao afirmar que as causas que contribuem para que a polícia moçambicana cometa a tortura no momento da investigação do crime são variadas, partindo da má formação dos agentes policiais em matéria de direitos humanos e das convenções contra a tortura, uma vez que os policias de formação básica não recebem instrução satisfatória nesses quesitos.

Dessa forma, $80 \%$ dos policiais que responderam ao questionário salientaram que a tortura é "ensinada" na formação, isto é, os recrutas são desnecessariamente punidos, maltratados e violentados por seus instrutores de modo que esse modelo de tratamento se enraíza no formando como parte da sua instrução policial, assim, depois de formado, o policial utiliza-se da mesma violência com que foi treinado, como se fosse algo normal.

Além disso, $20 \%$ dos policiais que responderam ao questionário, em uma das perguntas abertas, referiram o seguinte:

[...] somos ensinados na sala de aula a respeitar os direitos humanos na atuação policial, mas isso nada vale, pois, no campo de instrução o formando é torturado e o que aprendeu-se na sala de aula acaba sendo nulo, na medida em que somos ensinados sobre os direitos humanos na sala e no campo de instrução a realidade é outra.

A afirmação acima encontra sustento em Bedoya (2014, p. 10), para quem:

A formação dos maus policiais [...] começa quando ainda são recrutas. Imagine entrar para a polícia militar com vontade de defender a sociedade e lá dentro ser humilhado pelo mesmo grupo a que se queria pertencer? Isso mexe com a psique humana [...]. Os que cometem tal violência para com seus colegas, na maior parte das vezes também a sofreu. É o círculo vicioso, difícil de quebrar, muito comumente conhecido quando se fala de estupradores (que geralmente sofreram abusos na infância).

Assim, a violência que o policial sofre durante sua instrução é carregada até o seu campo de atividade, fazendo-o maltratar a população a qual jurou defender. Nesse sentido, o Artigo 20 da resolução número 34/169 da Assembleia Geral das Nações Unidas, de 17 de dezembro de 1979, afirma que:

Na formação dos policiais, os Governos e os
organismos de aplicação da lei devem conceder uma
atenção particular às questões de ética policial e de
direitos do homem, em particular no âmbito da
investigação, às alternativas para o uso da força ou
de armas de fogo, incluindo a resolução pacífica de
conflitos, ao conhecimento do comportamento de
multidões e aos métodos de persuasão, [...] bem
como aos meios técnicos, visando limitar a utilização
da força ou [...]. Os organismos de aplicação da lei
deveriam rever o seu programa de formação e
procedimentos operacionais à luz de casos
concretos.

Os entrevistados foram ainda mais longe ao afirmar por unanimidade que a falta de uma lei própria que defina e criminalize a tortura, assim como a falta do advogado do suspeito, também influencia no cometimento da tortura no momento da investigação criminal por parte dos policiais. Como dito, muitos suspeitos não têm condições para contratar um advogado particular, e os advogados designados pelo IPAJ muitas vezes não estão presentes no primeiro interrogatório policial, sendo um grande fator de influência para a tortura, seja física ou psicológica, no sentido de obrigar o suspeito a confessar o crime e, então, indiciá-lo.

Essa posição é defendida no relatório especial contra a tortura da ONU (Doc.A/56/156, 2001, par. 39 (d)) o qual afirma que nenhuma declaração ou confissão feita por pessoa privada 
de liberdade, que não tenha sido extraída na presença de um juiz ou de um advogado, terá valor probatório em juízo, exceto como prova contra aqueles acusados de terem obtido a confissão de um crime por meios ilícitos. O relatório referência ainda que os advogados da pessoa privada de liberdade devem ter acesso ao registro da ocorrência da detenção e custódia policial (quando a pessoa foi privada de liberdade e as razões para tal medida; quando foi informada dos seus direitos; sinais de ferimentos, doença mental etc.; quando o familiar, consulado ou advogado entrou em contato e visitou a pessoa detida; quando lhe foi oferecida comida; quando foi interrogada, transferida ou solta) (CPT/Inf/E (2002) 1 - Rev. 2006 English. The CPT Standards -2006. p.7, par. 40).

$\mathrm{O}$ direito universal de pessoas presas ou detidas a ter acesso a assessoramento jurídico é reconhecido no Artigo 14 do Pacto Internacional de Direitos Civis e Políticos (PIDCP) à medida que o acesso imediato a um advogado faz-se fundamental do ponto de vista da prevenção da tortura e de maus tratos. Por essa razão, a Comissão de Direitos Humanos enfatiza que a proteção da pessoa detida exige acesso imediato e regular a médicos e advogados (Observações finais do Comitê de Direitos Humanos: Geórgia, Doc. ONU CCPR/C/79/Ad.74, 1997, par. 28). A Comissão especifica ainda que o acesso a um advogado é uma salvaguarda básica contra abusos durante períodos de detenção longos, de maneira que a ausência de tais salvaguardas durante um longo período de detenção deixa a pessoa detida totalmente à mercê daqueles que a detêm $(\mathrm{CEDH}$, 1996, par. 83). Desse modo, se por questões de segurança o acesso a um advogado em particular for impedido, recomenda-se que se providencie acesso a outro advogado independente e confiável que não comprometa os interesses da investigação criminal (CPT/Inf/E (2002) 1 - Rev. 2006 English. The CPT Standards -2006.p.9, par 15).
Além disso, a fiscalização deficitária das celas da polícia e das penitenciárias por parte dos órgãos competentes (procuradores) para evitar casos de maus tratos e tratamentos desumanos nesses locais de detenção, bem como a transmissão da experiência do sistema inquisitório em que a confissão era a prova mãe na investigação criminal, por parte dos policiais mais antigos (provenientes da guerra de libertação nacional e da guerra civil) aos mais novos, também compõem as causas que contribuem para a tortura na investigação criminal.

Dessa forma, pode-se dizer que os entrevistados foram unânimes ao afirmar que a formação deficitária do polícia em Moçambique não se encontra simplesmente no patrulheiro, mas também nos superiores hierárquicos, que por vezes ordenam que seus subordinados usem de meios desumanos, como a tortura, em caso de o suspeito não confessar espontaneamente o crime, o que sugere que nem mesmo o superior hierárquico domina as leis sobre direitos humanos, assim como as convenções e regulamentos sobre a proibição da tortura.

\subsection{A inexistência de uma lei sobre a tortura em Moçambique e a sua implicação na responsabilização criminal de seus violadores}

A opinião de que se recorre ao Código Penal e ao Código do Processo Penal para incriminar os perpetradores da tortura - os quais são processados e condenados pela prática de "ofensas corporais voluntárias" - porque não há uma lei própria que a incrimine foi unanime entre os entrevistados, pois no entender dos entrevistados "por falta desse dispositivo legal, muitas vezes condenam-se os torturadores com o crime de ofensas corporais ou abuso de poder, ou ainda uso excessivo da força".

A LDH de Moçambique afirma que não basta o país ter ratificado convenções contra a tortura, deve existir uma lei própria que a defina e 
a incrimine, pois, a existência de um dispositivo legal contra a tortura permitirá que agentes da Lei e Ordem sejam punidos, exemplarmente, pela prática de tortura contra cidadãos detidos e suspeitos de terem praticado crime. Os juízes da Seção de Instrução Criminal da Província de Tete acrescentam que Moçambique baseia-se nos tratados e convenções internacionais para a proibição da tortura, contudo, nesses acordos e tratados internacionais não se encontra tipificado o crime de tortura e nem a sua moldura penal, razão pela qual se torna difícil incriminar um agente da polícia, que tenha praticado a tortura, apenas com base nesses dispositivos legais.

Os juízes salientam ainda que, por não existir uma lei que incrimine a tortura em Moçambique, para incriminar um policial ou agente do Estado por prática de tortura, verificase, em primeiro lugar, as circunstâncias ou o contexto em que o ato foi cometido: (i) se fora do exercício das suas funções, o policial pode ser incriminado por ofensas corporais, as quais podem ser simples ou graves, dependendo de cada caso, visto que fora do exercício das suas funções o policial é um cidadão comum, despido do poder do Estado; ou (ii) se a tortura for cometida por agente da polícia no exercício das suas funções, este pode ser incriminado a partir da lei militar, e todas as provas obtidas através da tortura passam a ser consideradas nulas, conforme está explícito no número 3 do Artigo $65^{\circ}$ da CRM.

Para o Procurador da Seção Criminal da Província de Tete, os casos de tortura perpetrados pela polícia contra um cidadão suspeito de ter cometido um ato criminal são tratados como crime de agressão física ou ofensas corporais previstos e punidos no Artigo $359^{\circ}$ e seguintes do Código Penal moçambicano, com devidos agravos por serem cometidos por um agente da

\footnotetext{
${ }^{3}$ Poder discricionário é uma determinada "liberdade" que o agente do Estado (Administrador) pode usar para agir em certo procedimento, respeitando os limites que a lei impõe. Liberdade na escolha conforme critérios de conveniência,
}

polícia conhecedor da lei e que, portanto, tem por obrigação cumpri-la e fazê-la cumprir.

Vemos que há uma divergência quanto ao tipo legal de crime que deve se imputar ao perpetrador da tortura; essa divergência reside no fato de não existir uma lei própria que defina e incrimine a tortura, razão pela qual o juiz incrimina a prática de tortura usando o poder discricionário. $^{3}$

Para a Anistia Internacional (2015, p. 6-), não se conhece em Moçambique nenhum caso julgado pelos tribunais que envolva o crime de tortura, ou melhor, os tribunais nunca processaram alguém pelo crime de tortura, o que, como sabemos, não significa que o crime não seja cometido no país, ao contrário, o que ocorre é que os policiais que cometem a tortura no exercício das suas funções são processados e julgados pelo crime de abuso de autoridade ou por excesso do uso da força, ou ainda, em alguns casos, por ofensas corporais qualificadas, visto que não existe uma lei que incrimine a prática de tortura.

De acordo com o Artigo $5^{\circ}$ do C.P Moçambicano, combinado com o Artigo $15^{\circ}$ do mesmo preceito, não são crimes os atos que não são qualificados como tais no Código Penal ou em outra legislação complementar ou lei avulsa e, nenhum fato, quer consista em ação ou omissão, pode julgar-se criminoso sem que uma lei anterior o qualifique como tal.

O princípio de legalidade consiste em uma garantia constitucional aos cidadãos moçambicanos de não serem sentenciados criminalmente, salvo em virtude de lei anterior que declare punível o ato ou omissão, bem como não sofrerem pena mais grave do que a fixada ao tempo da prática do crime ou medida de segurança fora dos casos previstos em lei anterior. Dessa forma, pode-se dizer que, em Moçambique,

oportunidade e justiça, próprios da autoridade, não ignorando os limites estabelecidos em lei, já que esses critérios não estão definidos em lei. 
a tortura não constitui crime, sendo que tudo o que não é proibido é tacitamente considerado algo lícito. Dito de outro modo: a razão pela qual a tortura não constitui crime em Moçambique reside na ausência de uma lei que a tipifique e incrimine.

De acordo com o Artigo $4^{\circ}$ da Convenção das Nações Unidas contra a Tortura e Outras Penas ou Tratamentos Cruéis, Desumanos ou Degradantes, os Estados devem assegurar que todos os atos de tortura sejam considerados crimes, de acordo com a lei penal nacional, e estabelecer jurisdição penal de tais atos, investigando-os e responsabilizando os responsáveis.

Com base no Artigo acima, podemos dizer que, apesar de Moçambique ter ratificado os tratados regionais e internacionais contra a tortura, há uma necessidade de criar uma lei própria que a defina e a incrimine; isso contribuiria para a responsabilização criminal uniforme dos responsáveis pela prática e para a prevenção e o combate à tortura no país.

A necessidade de criação de uma lei que defina e incrimine a tortura reside no fato de que a tortura é uma violação grave dos direitos humanos; onde há tortura, há violação de direitos humanos. Não faz sentido que os perpetradores dessa prática sejam punidos de igual maneira que aqueles que cometem crime de ofensas corporais, por exemplo. O mais grave é que a pena aplicada aos perpetradores dessa prática macabra não é uniforme, à medida que cada juiz aplica a pena de acordo com a sua convicção e conveniência devido, justamente, à falta da lei que defina e incrimine a tortura de modo a estipular sua moldura penal.

\section{CONCLUSÃO}

Este texto buscou analisar e trazer ações concretas que possam ser desenvolvidas pelos agentes da administração de justiça para evitar torturas e violações de direitos humanos no ato de investigação do crime em Moçambique.

Constatou-se que a má formação dos agentes policiais em matéria dos direitos humanos, a falta de uma lei própria que defina e criminalize a tortura, a falta do advogado por parte do suspeito e a fiscalização deficitária das celas da polícia e das penitenciárias por parte dos órgãos competentes (procuradores) para evitar casos de maus tratos e tratamentos desumanos nesses locais de detenção são as principais causas da prática de tortura pela PRM durante a investigação criminal.

Dessa forma, para o melhoramento da atuação policial na investigação criminal em Moçambique, a fim de combater a tortura, propõe-se o seguinte: (i) a criação de uma lei própria e exclusiva que defina, incrimine e traga uma moldura penal abstrata do crime de tortura, a fim de evitar que se recorra à interpretação extensiva do Código Penal para tipificá-lo e punilo. Assim, estar-se-ia também garantindo que os agentes do Estado que praticam a tortura não sejam punidos de diferentes maneiras de acordo com o poder discricionário do juiz responsável por julgar o caso; (ii) a implementação de medidas para garantir a proteção do torturado de modo a não sofrer represálias após a denúncia; (iii) maior investimento na formação básica dos policiais em matéria de direitos humanos, principalmente no que diz respeito às leis, tratados e convenções internacionais contra a tortura, maus tratos e tratamentos degradantes e desumanos, de modo a conscientizar os agentes da polícia a não pautar pela tortura no ato de investigação e esclarecimento do crime; (iv) a criação de condições para que todos os suspeitos se façam presentes com um advogado no primeiro interrogatório policial, e, em caso de o indiciado não possuir de meios para contratar um advogado particular, a garantia de um defensor oficioso por parte do governo que possa assegurar justiça ao suspeito (o Estado deve garantir que nenhuma 
confissão de crime realizada por pessoa privada de liberdade sem a presença de um advogado tenha valor probatório em juízo, exceto como prova contra aqueles acusados de terem obtido a confissão por meios ilícitos); e (v) a manutenção de uma revisão e de formações sistemáticas de regras de interrogatório, instruções, métodos e práticas, por parte do Estado aos agentes aplicadores das leis, bem como disposições aplicáveis à custódia e ao tratamento de pessoas submetidas a qualquer forma de detenção ou prisão, como um meio efetivo de prevenir casos de tortura e maus tratos.

\section{REFERÊNCIAS}

BECCARIA, Cesare. Dos Delitos e das Penas. Trad. Torrieri Guimarães. São Paulo: Martin Claret, 2007.

BEDOYA, Gleyde. Crime de tortura e abuso de poder praticado por policiais militares: qual a verdade? Qual a solução? JurisWay. Disponível em: 〈http://www.jurisway.org.br/v2/dhall.asp?id_dh=12888> Acesso em: 02 ago. 2015.

BRASIL. Lei $n^{o}$ 9.455, de 7 de abril de 1997.

BRUNO, Aníbal. Direito Penal. Parte Especial. v. I. Rio de Janeiro: Forense, 1966.

CAMPENHOU, Luc Van; QUIVY, Raymond. Manual de investigação em ciências sociais. 2. ed. Lisboa: Gadiva, 1998.

CONVENÇÃO INTERAMERICANA PARA PREVENIR E PUNIR A TORTURA. Cartagena das Índias, Colômbia, 1985.

CORTE EUROPEIA DE DIREITOS HUMANOS (CEDH). Aksoy v. Turquia. Sentença de 18 de dezembro de 1996.

CPT/INF/E (2002) 1 - Rev. 2006 English. The CPT Standards - "Substantive" sections of the CPTs General Reports. França, 2006. Disponível em: <http://www.cpt.coe.int/en/documents/eng-standardsscr.pdf>. Acesso em: 19 jul. 2015.

DiCIONÁRIO DE PORTUGUÊS. Latim. 2. ed. Portugal: Porto Editora, 2000.

FLOWERS, Nancy et al. Direitos humanos aqui e agora Comemoração da Declaração Universal dos Direitos Humanos: uma contribuição para a década das nações unidas para a educação dos direitos humanos, 1995-2004. Disponível em: <http://www.amnistiainternacional.pt/files/documentacao/DH_Aqui_e_Agora.pdf>. Aceso em: 03 fev. 2015.

FOUCAULT, Michael. Vigiar e punir: nascimento da prisão. Trad. Raquel Ramalhete. 42. ed. Rio de Janeiro: Petrópolis, 2014.

GOMES, Luiz Flávio. A eficácia da lei da tortura. Da tortura: aspectos conceituais e normativos. CEJ, Brasília, n. 14, mai./ago. 2001. 
HUNGRIA, Nelson. Comentários ao Código Penal. v. 5. Rio de Janeiro: Forense, 1958.

LIGA MOÇAMBICANA DOS DIREITOS HUMANOS (LDH). Relatório dos Direitos Humanos. Moçambique, 2004.

MAIA, Gonçalves Manuel Lopes. Código Penal Português: anotado e comentado. 18. ed. Lisboa: Almedina, 2009.

MARQUES, José Frederico. Elementos do direito processual penal. v. I. Campinas: Booksheller, 1997.

MATTOSO, Glauco. O que é Tortura? São Paulo: Brasiliense, 1984.

MICHAEL, Maria Helena. Metodologia e pesquisa científica em ciências sociais: um guia prático para acompanhamento da disciplina e elaboração de trabalhos monográficos. São Paulo: Atlas, 2005.

MOÇAMBIQUE PARA TODOS. Polícia de Investigação Criminal continua a mandar torturar detidos nas esquadras. Disponível em:

<http://macua.blogs.com/moambique_para_todos/2012/07/pol\%C3\%ADcia-de-

investiga\% $3 \% \mathrm{~A} 7 \% \mathrm{C} 3 \% \mathrm{~A} 3 \mathrm{o}-$-criminal-continua-a-mandar-torturar-detidos-nas-esquadras.html>.

Acesso em: 16 abr. 2015.

MOÇAMBIQUE. Apresentação ao Comité das Nações Unidas contra a Tortura. $51^{\mathrm{a}}$ sessão do comitê contra a tortura das nações unidas (28 de outubro - 22 de novembro de 2013). Londres: Amnesty International Publications, 2013. Disponível em:

<https://www.amnesty.org/download/Documents/12000/afr410062013pt.pdf>. Acesso em: 17 abr. 2015.

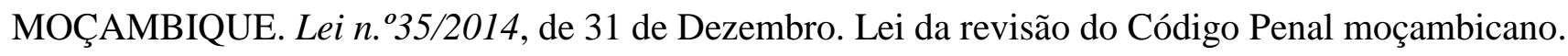
2014.

MOÇAMBIQUE. Regulamento Disciplinar da Polícia Popular de Moçambique. Diploma Ministerial Número 41/89 de 17 de maio.

MORAES, Alexandre. Direitos Humanos Fundamentais: teoria geral. 4. ed. São Paulo: Atlas, 2002.

NORONHA, Edgard Magalhães. Direito Penal. v. 2. São Paulo: Saraiva, 1977.

ORDEM DOS ADVOGADOS DE MOÇAMBIQUE (OAM). Discurso de Abertura do Ano Judicial. 2015. Disponível em:

<http://www.oam.org.mz/wp-content/uploads/DiscursoDeAberturaAnoJudicial2015.pdf $>$. Acesso em: 10 abr. 2015.

ORGANIZAÇÃO DAS NAÇÕES UNIDAS (ONU). Assembleia Geral. Resolução número 34/169. 17 de dezembro, 1979.

ORGANIZAÇÃO DAS NAÇÕES UNIDAS (ONU). Convenção das Nações Unidas contra a Tortura e Outros Tratamentos ou Penas Cruéis, Desumanos ou Degradantes. Resolução número 39/46 da Assembleia Geral das Nações Unidas. 1984. 
ORGANIZAÇÃO DAS NAÇÕES UNIDAS (ONU). Declaração Universal dos Direitos do Homem, adotada e proclamada pela Resolução 217A (III) da Assembleia Geral das Nações Unidas, em 10 de dezembro de 1948.

ORGANIZAÇÃO DAS NAÇÕES UNIDAS (ONU). Kelly v Jamaica, (253/1987), 8 de abril de 1991, Relatório da Comissão de Direitos Humanos, (A/46/40), 1991.

ORGANIZAÇÃO DAS NAÇÕES UNIDAS (ONU). Observações finais do Comitê de Direitos Humanos. Doc. ONU CCPR/C/79/Ad.74, 9 de abril de 1997. Geórgia, 1997.

ORGANIZAÇÃO DAS NAÇÕES UNIDAS (ONU). Párkányi v Hungria (410/1990), 27 de julho de 1992, Relatório da Comissão de Direitos Humanos, (A/47/40), 1992.

ORGANIZAÇÃO DAS NAÇÕES UNIDAS (ONU). Relatório do Relator Especial contra a Tortura, ONU Doc. A/56/156, julho de 2001, par. 39 (d).

ORGANIZAÇÃO DOS ESTADOS AMERICANOS (OEA). Relatório sobre a Situação dos Direitos Humanos em um Segmento da População da Nicarágua, de origem Miskito. OEA Ser.L/V/11.62, doc. 10, rev. 3, 1983.

PEREZLUÑO, Antonio Enrique. Derechos Humanos, estado de derecho y Constitución. 3. ed. Madri: Teccnos, 1990.

VERDADE. LDH denuncia aumento de casos de torturas nas Esquadras. Disponível em: $<$ http://www.verdade.co.mz/nacional/8444-ldh-denuncia-aumento-de-casos-de-torturas-nasesquadras>. Acesso em: 10 fev. 2014.

VERRI, Pietro. Observações sobre a tortura. Trad. Federico Carotti. 2. ed. São Paulo: Martins Fontes, 2000.

\section{Detalhes sobre as entrevistas efetuadas:}

Entrevista efetuada no dia 02/04/2015 ao Juiz da Secção de Instrução Criminal - Moçambique.

Entrevista efetuada no dia 03/04/2015 ao pessoal do Gabinete Jurídico do Instituto de Patrocínio e Assistência Jurídica (IPAJ) - Moçambique.

Entrevista efetuada no dia 06/04/2015 à Juíza da 2ª Secção Criminal da Cidade de Tete.

Entrevista efetuada no dia 10/04/2015 ao Delegado da Liga dos Direitos Humanos - Moçambique.

Entrevista efetuada no dia 16/04/2015 ao Magistrado do Ministério Público da Seção Criminal Moçambique.

Questionário aplicado no dia 12/04/2015 aos policiais da Republica de Moçambique afetos no comando provincial da cidade de Tete. 
